\title{
Radiofrequencies for painful total knee Arthroplasty: rationale and applications: A review
}

\author{
Bistolfi $\mathrm{A}^{1 *}$, Zorzolo $\mathrm{I}^{1}$, Rold $\mathrm{I}^{1}$, Verna $\mathrm{V}^{1}$, Magistroni $\mathrm{E}^{1}$ and Ferracini $\mathrm{R}^{2}$ \\ ${ }^{1}$ Department of Orthopaedic, Traumatology and Rehabilitation Trauma Centre, CTO Hospital, University Hospital City of Health and Science of Turin, Italy Via \\ Zuretti 29, 10126 Torino, Italy \\ ${ }^{2}$ Department of Combined Surgical Sciences and Diagnostics University of the Studies of Genova and IRCCS San Martino Largo R. Benzi, 8 Genova (GE), Italy
}

\begin{abstract}
Total knee arthroplasty ensures patients a safe recover of function and pain relief. It is performed on millions of patients worldwide. Nevertheless, in a certain percentage of case there is an unexplainable persistence of pain in presence of a well-performed surgery. This is called mystery knee or persistent postsurgical pain (PPSP) and the surgical treatment is difficult since the factors to correct are unknown. Radiofrequencies are used for the treatment of chronic nervous pain and also in some cases of osteoarthritis. They function with well-demonstrated and safe physical and microbiological processes. Therefore, the idea to apply radiofrequencies on one or several nervous braches of the knee (superolateral, superomedia, middle, inferolateral (recurrent), inferomedial and lateral retinacular) is quite interesting and can provide pain relief for this particular group of patients. The procedure is safe and not permanent and can be repeated if necessary. There are not many studies on this topic, but the first results report good outcomes. Costs may be an issue, but once the patient has no pain, the rehabilitation is more effective and the surgery con is postponed or deleted. This review discusses the basis of PPSP after knee surgery, the biological mechanism of action of the radiofrequencies and the clinical application after total knee arthroplasty.
\end{abstract}

\section{Introduction}

\section{Persistent postsurgical pain (PPSP)}

Total knee arthroplasty (TKA) is one of the most commonly performed orthopedic procedures. In 2010 among the older patient in the United States the per capita number of primary total knee replacements was 62 per 10,000 Medicare enrolees, twice as compared to 1991 [1] and the number of TKA performed annually in the United States is expected to grow by $673 \%$ by 2030 [2]. The main indication for total knee arthroplasty is for the relief of pain associated with arthritis of the knee in patients who have failed non-operative treatments (up to $84.9 \%$ of TKA [3]). Other conditions leading to TKA include inflammatory arthritis, osteonecrosis, fracture, malignancy and others. Although outcomes TKA are generally good [4-7], 19\%-20\% of the patients continue to report clinically significant pain and/or dissatisfaction [8-10] and persistent postsurgical pain (PPSP) appears to be the primary predictor of dissatisfaction [11]. PPSP is defined by the International Association of the Study of Pain as pain after surgical intervention that lasts at least 2 months, with other causes of pain being excluded, such as pain from a condition preceding the surgery. The most common location for residual pain after TKA is anteriorly, because residual pain has been associated with patellofemoral disorders. Patellofemoral disorders include: an un-resurfaced patella, component malalignment with patellar maltracking, crepitation and patellar clunk syndrome and avascular necrosis of the patella. Other possible causes of residual pain include: low-grade infection, instability, aseptic loosening, and hypersensitivity to metal or cement, complex regional pain syndrome, pseudo aneurysm [12]. Identify the etiology of the residual pain can be a difficult diagnostic challenge and up to $10 \%$ to $15 \%$ of patients may have unexplained pain. Efforts to identify the explanations for these suboptimal pain outcomes are an active area of research. Possible explanations for such persistent pain complaints include inappropriate expectations, technical failures of the procedure, pain from other sources, poor pain-coping skills, and others [9-10].

The nature of PPSP remains unclear, but iatrogenic neuropathic pain caused by incision and nerve injury is thought to be the most common cause of PPSP [13]. The reasons for nerve injury after TKA do not only involve direct surgical trauma of the infrapatellar branch of the saphenous nerve (84\%) or more exceptional the peroneal nerve [14], but may also be caused by the tourniquet during the procedure or peripheral nerve blocks used for peri-operative analgesia [15]. Not all nerve lesions will cause pain and PPSP associated with nerve injury will only develop in predisposed individuals [16].

In case of PPSP identify the etiology can be challenging and patients must undergo extensive anamnestic collection, including a detailed description of the type of pain, psychological exploration, clinical evaluation and diagnostic exams including radiographs and special imaging, laboratory tests, joint aspiration and test infiltrations [16]. If after performing an appropriate diagnostic algorithm, etiology of PPSP cannot be identified, patients should have an intensive trial of conservative therapy for at least 3 months including pain control with painkillers and physical therapy. The physiotherapy should specifically focus on the underlying problem and cause of pain. Most of these

Correspondence to: Alessandro Bistolfi, MD, Department of Orthopaedic, Traumatology and Rehabilitation Trauma Centre, CTO Hospital, University Hospital City of Health and Science of Turin, Italy; E-mail: abistolfi@cittadellasalute.to.it

Key words: total knee arthroplasty, osteoarthritis, neuropathic pain

Received: October 27, 2017; Accepted: November 17, 2017; Published: November 21, 2017 
patients show muscular atrophy and/or imbalances, which should be addressed also. Daily home exercises and training programmes in combination with braces and other supporting devices should be performed [17].

Since PPSP in difficult to treat with surgery because the cause to treat is unknown, these patients are usually referred to the rehabilitation or to the therapy $f$ chronic pain. The possibility to reduce or to eliminate the pain with the treatment with radiofrequencies is quite interesting because potentially link the demonstrated efficacy of radiofrequencies with the possibility to avoid a surgery whose effects may be not satisficing for the patients.

\section{Radiofrequencies: rationale and biology}

Since it is believed that PPSP is neuropathic, radiofrequency (RF) applied to the damaged nerve is a possible therapy. RF energy is the biophysical conception established to describe high-frequency alternating electrical currents (with a frequency ranging from $300 \mathrm{kHz}$ to $3 \mathrm{MHz}$ ) and their impact on biological tissue [18]. In the course of current RF application, electromagnetic energy is first converted in cells to kinetic energy then to thermal energy. Thermal energy production causes tissue heating around the active electrodes [19]. RF treatments are currently categorized into continuous radiofrequency (CRF) and pulsed radiofrequency (PRF). CRF uses high-frequency alternating current to induce tissue destruction close the electrode tip. The main advantages of CRF treatment seem to be its effectiveness and high pain relief rate [20]. However, because of the exposure of nerve tissues to higher temperatures in CRF treatment leading to structural damage, the disadvantages include numbness and anesthesia dolorosa [20-21].

PRF is a novel therapeutic modality with many potential applications in pain management that uses radiofrequency current in short (20 ms), high-voltage bursts; the "silent" phase (480 ms) of PRF allows time for heat elimination, generally keeping the target tissue below $42^{\circ} \mathrm{C}$. RF induced thermal damage to tissue is reversible when the achieved cellular temperature is below $45^{\circ} \mathrm{C}$. The electrode e tissue temperatures are controlled by the RF generator by changing the electric voltage, usually kept at an ideal value of $45 \mathrm{~V}$, by changing the pulse duration and/or frequency or by the operator injecting physiological solution in the application area. Commercially available RF generators provide PRF signals with pulse durations ranging from 5 to $50 \mathrm{~ms}$ and pulse frequency ranging from 1 to $10 \mathrm{~Hz}$, but the most commonly used sequence is a pulse frequency of $2 \mathrm{~Hz}$ and a pulse width of $20 \mathrm{~ms}$. The intrinsic radiofrequency oscillation frequency within each pulse is still about $420 \mathrm{kHz}$ [22]. Pulse-dose radiofrequency (PDRF) is a technical evolution of PRF. In PRF, technique pulses parameters change if the tissue temperature exceeds $42^{\circ} \mathrm{C}$. When PDRF is performed, the RF generator can provisionally stop the pulses; however, their number and their parameters are always constant.

The mechanism by which PRF causes pain relief in the absence of significant heat-induced tissue damage is debatable. The notion that the electrical fields generated by PRF can affect neuronal membranes is supported by neurophysiologic studies that demonstrate PRF changes synaptic signaling and causes electroporation, which is the process of deformation, pores creation, and if high enough, the rupture of the cell membranes [23]. Lower electric field phenomena, which are the leading explanation for PRF effects, may theoretically result in long-term depression (LTD), as possible sequelae of conditioning stimulation [22-23]. This, however, does not explain for the observed effects of $\mathrm{PRF}$ in applications where there is no nervous tissue anywhere near the electrode tip, such as in intra-articular PRF. One histopathologic study on the effects of PRF delivered at $42^{\circ} \mathrm{C}$ on the rat sciatic nerve, showed no structural changes aside from transient endoneurial edema and collagen deposition [24]. More recent studies on ultrastructural axonal changes showed microscopic damage after PRF exposure, abnormal membranes and morphology of mitochondria, and disruption and disorganization of microfilaments and microtubules [25]. These histological findings are believed to be a result of the high transmembrane potentials generated with tissues exposed to the electrical fields during PRF application. These findings suggest that PRF treatment adjacent to the nerve thanks to electric field effects can reduce or alleviate neuropathic pain.

In addition to the histological and ultrastructural axonal findings in PRF, and the animal studies demonstrating PRF effects, there are also convincing biochemical basis for PRF effects. A popular theory suggests that the rapidly changing electric fields produced by PRF alter the transmission of pain signals via a pathway involving c-Fos, a so-called immediate early gene [26]. However the evidences around the c-Fos induction theories are few and lack controlled clinical trials and might have not a role in pain control. Expression of $\mathrm{c}$-fos is no more than a marker of increased cellular metabolic activity; it is not even specific for nociceptive pathways. It indicates only that cells are activated. It does not distinguish between inhibitory and excitatory activity. It is not evidence that patients will be relieved of their pain [27]. More PRF biological effect include the upregulation of ATF-3 (activating transcription factor-3), another marker of "cellular stress" [28] and increase in the descending noradrenergic and serotonergic inhibitory pathways, which are intimately involved in the modulation of neuropathic pain [29]. Despite the fact that PRF might operate by modulating pain perception rather than directly destroying neural tissue or altering its electrical activity, at present it is difficult to relate the results of these experiences to clinical data.

\section{Clinical application for radiofrequencies}

Neurological pain: PRF has been used in the treatment for neuropathic pain caused by different conditions such as: post herpetic neuralgia [29], trigeminal neuralgia [30], cervical radicular pain [31], lumbosacral radicular pain [32], lumbar zygapophyseal joint pain [21].

Osteoarthritis: Studies were performed to test PRF efficacy in the treatment of osteoartrithis (OA) using an intra-articular electrode. Sluijter ME, et al. [33] successfully performed PRF in different joints (cervical facet, shoulder, knee, sacroiliac, atlanto-axial, and radiocarpal joints) in 6 patients with OA, reporting excellent results from all application in mid and long term. Following their experience, more Authors reported a decrease of painful symptomatology in the knee [34,35], the atlanto-axial [36], the glenohumeral [37-38], the trapeziometacarpal and first metatarso-phalangeal joints [38]. Knee intraarticular PRF significantly improved pain control (VAS or NRS) and quality of life (WOMAC score) at all follow-ups from one month to 10 months [33-35,38]. However these results were achieved in small studies and none of them is a randomized controlled trial (RCT).

\section{Radiofrequencies and knee: a) theory}

PRF, since it does not damage tissue, has been used for the treatment of peripheral nerves pain syndromes lowering the risks of neuritis, deafferation pain, motor deficit and unintentional damage to nontargeted tissue associated with surgical, chemical, cryogenic or thermal peripheral nerve destruction [39]. PRF in the treatment of chronic knee pain has been used either intra-articularly [33-35, 38] or directly on the peripheral nerve causing the symptoms [40-46]. 
The latter strategy in order to be effective requires precise identification of neural nociceptive afferent pathways originating from the knee in order to interrupt the pain. Branches of the femoral, sciatic and obturator nerves supply the knee capsule. Knee capsule innervation can be divided in two groups: anterior and posterior. The posterior group originates from the sciatic nerve, mainly by its tibial branch, and in a variable amount of cases by branches from the posterior branch of the obturator nerve. These latter branches are described as forming a plexus closely associated with the popliteal vessels. The anterior group originates from branches of the femoral nerve, through muscular branches to vastus medialis, vastus lateralis, and vastus intermedius and the saphenous nerve, and the common peroneal nerve by its recurrent branch and its lateral retinacular branch. According to a systematic dissection of human cadaver specimens, the anterior knee capsule innervation can be described as:

1. Superolateral branch: originating from the innervation to vastus lateralis and found in relation to the deep surface of this muscle and distally coming in close proximity to the junction of the lateral epicondyle and the shaft of the femur and distributing on the superolateral anterior aspect of the capsule;

2. Superomedial branch: originating from nerve branches to vastus medialis and found on the deep surface of this muscle in close proximity to the junction of the medial epicondyle and the shaft of the femur and distributing to the superomedial anterior aspect of the capsule;

3. Middle branch, also known as medial retinacular branch: originating from nerve branches supplying the vastus intermedius and found running between this muscle and the anterior aspect of the distal femur in the direction of the suprapatellar pouch of the knee capsule;

4. Inferolateral (recurrent) branch of the common peroneal nerve: as this nerve passes just inferior to the fibular head, it splits into superficial and deep branches, but also provides a constant recurrent branch to the capsule, which distributes to the inferolateral anterior aspect of the capsule;

5. Inferomedial branch of the saphenous nerve: originating from the subpatellar branch and running anteriorly from the medial side of the knee in a trajectory very close to the junction between themedial condyle of the tibia and its shaft

6. Lateral retinacular nerve branch of the common peroneal nerve: this branch is given off by the common peroneal at the level of the lateral side of the joint and distributes around the lateral aspect of the capsule [40].

7. Considering its complex innervation, it is expected to be technically difficult to locate specific nerves and to achieve a desired clinical outcome of pain relief.

\section{Radiofrequencies and knee: b) application and clinical data}

In order to increase the chances of appropriate pain relief some Authors [41-42] tested an almost circumferential anterior nerve block involving three genicular branches: superior lateral (SLGN), superior medial (SMGN), and inferior medial (IMGN). These studies tested neurotomy procedures using CRF on patients with OA [41] with PPSP after TKR [42]. Considering the close proximity of the inferolateral branch to the common peroneal nerve branch, none of the studies specifically targeted it to avoid loss of motor function. Kesikburun S, et al. [43] applied PRF to the SMGN and the IMGN only obtaining a significant pain relief and function improvement in patients with OA suggesting that only these 2 genicular nerves are involved in clinically evident knee pain related with medial compartment knee OA. A more extensive approach was tested by Vas L, et al. [44] targeting large nerves including common peroneal nerve and popliteal plexus sensory and motor nerve block obtaining a significant improvement in pain, stiffness, swelling, functionality and even in radiographical appearance in OA knees. Two more studies targeted large nerves: Akbas, et al. [45] targeted the saphenous nerve, and thus the IPSN at the tibial tuberosity, while Fucci, et al. [46] targeted the sciatic nerve just prior to the division into tibial and peroneal nerves. Despite the technique differences all studies obtained significant pain relief and function improvement for the treatment of painful chronic knee OA with PRF [43-46].

Following the success obtained with the treatment of knee OA, RF has been studied for PPSP after TKA [42,46-49]. The experiences in this field of application are few and require larger studies and RCT. To Our knowledge Protzman, et al. [42] were the first to describe a successful case of inferomedial, superomedial, and superolateral genicular branches RF neurotomy. Specifically PRF was tested on two patients in combination with dry needeling following the theory PPSP is a neuromyopathic phenomenon rather than being purely neuropathic [47]. PRF was applied to the large nerves suppling the anterior knee capsule (saphenous nerve, tibial nerve, common peroneal nerve peripatellar, subsartorial, and popliteal plexuses) obtaining significant pain relief and function improvement. Albayrak I, et al. [48] evaluated the addition of PRF on L4 dorsal root ganglion to TENS and physiotherapy reporting significant lasting pain relief especially in those patients with a neuropathic pain component that responded to the diagnostic nerve bloc. Diagnostic nerve block has been used inconsistently with only few studies clearly stating its application [42-43,47].

\section{Conclusions}

Radiofrequencies in the treatment of painful knee prostheses play a significant role in improving the quality of life of patients with confirmed efficacy in all cases associated with a reduction in perceived pain. The data collected show that the period of pain reduction lasts for months after treatment; then it undergoes a bending phase with gradual worsening of the painful symptoms, however lower than the values found before the radiofrequency procedure. Reducing analgesic drugs (mostly opiates), even six months after treatment, improves the quality of life for the absence of side effects that may interfere with a normal life-cycle relationship for many patients. Materials' costs, given the reduction in the use of medicines and in relation to the recovery of an active life, appear to be sustainable even if the improvement of the painful symptoms is temporary. This procedure, since it does not cause irreversible lesions and is well tolerated by the patient, is repeated with significant effect on the pain. Rehabilitation, performed after pain reduction or remission, has proven to be a key element for recovering the function and for restoring a qualitatively acceptable life.

\section{References}

1. Cram P, Lu X, Kates SL, Singh JA, Li Y, et al. (2012) Total knee arthroplasty volume, utilization, and outcomes among Medicare beneficiaries, 1991-2010. JAMA 308: 12271236. [Crossref]

2. Kurtz S, Ong K, Lau E, Mowat F, Halpern M (2007) Projections of primary and revision hip and knee arthroplasty in the United States from 2005 to 2030. J Bone Joint Surg Am 89: 780-785. [Crossref]

3. Lenza M, Ferraz Sde B, Viola DC, Filho RJG, Neto MC, et al. (2013) Epidemiology of total hip and knee replacement: a cross-sectional study. Einstein (Sao Paulo) 11: 197-202. [Crossref]

4. Bistolfi A, Massazza G, Rosso F, Deledda D, Gaitoet V, et al. (2011) Cemented fixedbearing PFC total knee arthroplasty: survival and failure analysis at $12-17$ years. $J$ Orthop Traumatol 12: 131-136. [Crossref] 
5. Bistolfi A, Lustig S, Rosso F, Dalmasso P, Crova M, et al. (2013) Results with 98 Endo-Modell rotating hinge prostheses for primary knee arthroplasty. Orthopedics 36 : e746-52. [Crossref]

6. Bistolfi A, Massazza G, Lee GC, Deledda D, Berchialla P, et al. (2013) Comparison of fixed and mobile-bearing total knee arthroplasty at a mean follow-up of 116 months. $J$ Bone Joint Surg Am 95: e83. [Crossref]

7. Bistolfi A, Lee GC, Deledda D, Rosso F, Berchialla P, et al. (2014) NexGen ${ }^{\circledR}$ LPS mobile bearing total knee arthroplasty: 10-year results. Knee Surg Sports Traumatol Arthrosc 22: 1786-1792. [Crossref]

8. Bistolfi A, Bettoni E, Aprato A, Milani P, Berchialla P, et al. (2015) The presence and influence of mild depressive symptoms on post-operative pain perception following primary total knee arthroplasty. Knee Surg Sports Traumatol Arthrosc 25: 2792-2800. [Crossref]

9. Scott CE, Howie CR, MacDonald D, Biant LC (2010) Predicting dissatisfaction following total knee replacement: a prospective study of 1217 patients. J Bone Joint Surg Br 92: 1253-1258. [Crossref]

10. Park CN, White PB, Meftah M, Ranawat AS, Ranawat CS (2016) Diagnostic Algorithm for Residual Pain After Total Knee Arthroplasty. Orthopedics 39: e246-252

11. Kehlet H, Jensen TS, Woolf CJ (2006) Persistent postsurgical pain: risk factors and prevention. Lancet 367: 1618-1625. [Crossref]

12. Henningsen MH, Jaeger P, Hilsted KL, Dahl JB (2013) Prevalence of saphenous nerve injury after adductor-canal-blockade in patients receiving total knee arthroplasty. Acta Anaesthesiol Scand 57:112-117. [Crossref]

13. Kinghorn K, Ellinas H, Barboi AC, Dolinski SY (2012) Case scenario: nerve injury after knee arthroplasty and sciatic nerve block. Anesthesiology 116: 918-923. [Crossref]

14. Lavand'homme P (2011) The progression from acute to chronic pain. Curr Opin Anaesthesiol 24: 545-550. [Crossref]

15. Grosu I, Lavand'homme P, Thienpont E (2014) Pain after knee arthroplasty: an unresolved issue. Knee Surg Sports Traumatol Arthrosc 22: 1744-1758. [Crossref]

16. Hofmann S, Seitlinger G, Djahani O, Pietsch M (2011) The painful knee after TKA a diagnostic algorithm for failure analysis. Knee Surg Sports Traumatol Arthrosc 19: 1442-1452. [Crossref]

17. Seyler TM, Marker DR, Bhave A, Plate JF, Marulanda GA, et al. (2007) Functional problems and arthrofibrosis following total knee arthroplasty. J Bone Joint Surg Am 89: 59-69. [Crossref]

18. Ihnát P, Ihnát Rudinská L, Zonča P (2014) Radiofrequency energy in surgery: state of the art. Surg Today 44: 985-991. [Crossref]

19. Massarweh NN, Cosgriff N, Douglas PS (2006) Electrosurgery: history, principles, and current and future uses. J Am Coll Surg 202: 520-530. [Crossref]

20. Erdine S, Ozyalcin NS, Cimen A, Celik M, Talu GK, et al. (2007) Comparison of pulsed radiofrequency with conventional radiofrequency in the treatment of idiopathic trigeminal neuralgia. Eur J Pain 11: 309-313. [Crossref]

21. Kroll HR, Kim D, Danic MJ, Sankey SS, Gariwala M, et al. (2008) A randomized, doubleblind, prospective study comparing the efficacy of continuous versus pulsed radiofrequency in the treatment of lumbar facet syndrome. J Clin Anesth 20: 534-537. [Crossref]

22. Sluijter ME. Pulsed radiofrequency (2001) In Radiofrequency, part 1, Fliovopress SA, Meggen (LU), Switzerland, 55-68.

23. Cosman ER Jr, Cosman ER Sr (2005) Electric and thermal field effects in tissue around radiofrequency electrodes. Pain Med 6: 405-424. [Crossref]

24. Podhajsky RJ, Sekiguchi Y, Kikuchi S, Myers RR (2005) The histologic effects of pulsed and continuous radiofrequency lesions at 42 degrees $\mathrm{C}$ to rat dorsal root ganglion and sciatic nerve. Spine (Phila Pa 1976) 30: 1008-1013. [Crossref]

25. van Zundert J, de Louw AJ, Joosten EA, Kessels AG, Honig W, et al. (2005) Pulsed and continuous radiofrequency current adjacent to the cervical dorsal root ganglion of the rat induces late cellular activity in the dorsal horn. Anesthesiology 102: 125-131. [Crossref]

26. Richebe P, Rathmell JP, Brennan TJ (2005) Immediate early genes after pulsed radiofrequency treatment: neurobiology in need of clinical trials. Anesthesiology 102:13. [Crossref]

27. Hamann W, Abou-Sherif S, Thompson S, Hall S (2006) Pulsed radiofrequency applied to dorsal root ganglia causes a selective increase in ATF3 in small neurons. Eur J Pain 10: 171-176. [Crossref]

28. Hagiwara S, Iwasaka H, Takeshima N, Noguchi T (2009) Mechanisms of analgesic action of pulsed radiofrequency on adjuvant-induced pain in the rat: roles of descending adrenergic and serotonergic systems. Eur J Pain 13: 249-252. [Crossref]
29. Wang D, Zhang K, Han S, Yu L (2017) PainVision ${ }^{\circledR}$ Apparatus for Assessment of Efficacy of Pulsed Radiofrequency Combined with Pharmacological Therapy in the Treatment of Postherpetic Neuralgia and Correlations with Measurements. Biomed Res Int 2017: 5670219.

30. Thapa D, Ahuja V, Dass C, Verma P (2015) Management of refractory trigeminal neuralgia using extended duration pulsed radiofrequency application. Pain Physician 18: E433- E435. [Crossref]

31. Van Zundert J, Patijn J, Kessels A, Lamé I, van Suijlekom H (2007) Pulsed radiofrequency adjacent to the cervical dorsal root ganglion in chronic cervical radicular pain: A double blind sham controlled randomized clinical trial. Pain 127: 173-182. [Crossref]

32. Shanthanna H, Chan P, McChesney J, Thabane L, Paul J (2014) Pulsed radiofrequency treatment of the lumbar dorsal root ganglion in patients with chronic lumbar radicular pain: A randomized, placebo-controlled pilot study. J Pain Res 7: 47-55. [Crossref]

33. Sluijter ME, Teixeira A, Serra V, Balogh S, Schianchi P (2008) Intra-articular application of pulsed radiofrequency for arthrogenic pain: report of six cases. Pain Pract 8: 57-61. [Crossref]

34. Karaman H, Tüfek A, Kavak GÖ, Yildirim ZB, Uysal E, et al. (2011) Intra-articularly applied pulsed radiofrequency can reduce chronic knee pain in patients with osteoarthritis. J Chin Med Assoc 74: 336-340. [Crossref]

35. Masala S, Fiori R, Raguso M, Morini M, Calabria E, et al. (2014) Pulse-dose radiofrequency for knee osteoartrithis. Cardiovasc Intervent Radiol 37: 482-487. [Crossref]

36. Halim W, Chua NH, Vissers KC (2010) Long-term pain relief in patients with cervicogenic headaches after pulsed radiofrequency application into the lateral atlantoaxial (C1e2) joint using an anterolateral approach. Pain Pract 10: 267e71.

37. Ozyuvaci E, Akyol O, Acikgoz A, Leblebici H (2011) Intraarticular pulsed mode radiofrequency lesioning of glenohumeral joint in chronic shoulder pain: 3 cases. Korean J Pain 4: 239-241. [Crossref]

38. Schianchi PM, Sluijter ME, Balogh SE (2013) The Treatment of Joint Pain with Intraarticular Pulsed Radiofrequency. Anesth Pain Med 3: 250-255. [Crossref]

39. Rohof OJ (2002) Radiofrequency treatment of peripheral nerves. Pain Pract 2: 257 260. [Crossref]

40. Franco CD, Buvanendran A, Petersohn JD, Menzies RD, Menzies LP (2015) Innervation of the Anterior Capsule of the Human Knee: Implications for Radiofrequency Ablation Reg Anesth Pain Med 40: 363-368. [Crossref]

41. Choi WJ, Hwang SJ, Song JG, Leem JG, Kang YU, et al. (2011) Radiofrequency treatment relieves chronic knee osteoarthritis pain: a double-blind randomized controlled trial. Pain 152: 481-487. [Crossref]

42. Protzman NM, Gyi, Malhotra AD, Kooch JE (2014) Examining the feasibility of radiofrequency treatment for chronic knee pain after total knee arthroplasty. PMR 6 : 373-376. [Crossref]

43. Kesikburun S, Yaşar E, Uran A, Adigüzel E, Yilmaz B (2016) Ultrasound-Guided Genicular Nerve Pulsed Radiofrequency Treatment For Painful Knee Osteoarthritis: A Preliminary Report. Pain Physician 19: E751-9. [Crossref]

44. Vas L, Pai R, Khandagale N, Pattnaik M (2014) Pulsed radiofrequency of the composite nerve supply to the knee joint as a new technique for relieving osteoarthritic pain: a preliminary report. Pain Physician 17: 493-506. [Crossref]

45. Akbas M, Luleci N, Dere K, Luleci E, Ozdemir U, et al. (2011) Efficacy of pulsed radiofrequency treatment on the saphenous nerve in patients with chronic knee pain. $J$ Back Musculoskelet Rehabil 24: 77-82. [Crossref]

46. Fucci R, Pascual-Ramírez J, Martínez-Marcos A, Mantecón JM (2013) Ultrasoundguided sciatic nerve pulsed radiofrequency for chronic knee pain treatment: a novel approach. J Anesth 27: 935-938. [Crossref]

47. Vas L, Khandagale N, Pai R (2014) Successful management of chronic postsurgical pain following total knee replacement. Pain Med 15: 1781-1785. [Crossref]

48. Albayrak I, Apiliogullari S, Dal CN, Levendoglu F, Ozerbil OM (2017) Efficacy of Pulsed Radiofrequency Therapy to Dorsal Root Ganglion Adding to TENS and Exercise for Persistent Pain after Total Knee Arthroplasty. J Knee Surg 30: 134-142. [Crossref]

Copyright: (C)2017 Bistolfi A. This is an open-access article distributed under the terms of the Creative Commons Attribution License, which permits unrestricted use, distribution, and reproduction in any medium, provided the original author and source are credited. 